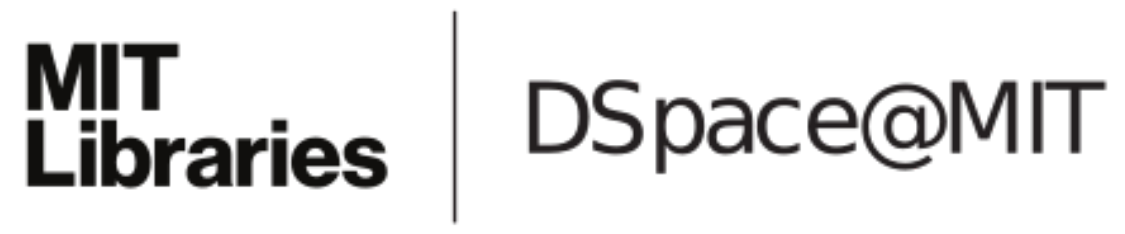

MIT Open Access Articles

Equity and emissions trading in China

The MIT Faculty has made this article openly available. Please share how this access benefits you. Your story matters.

Citation: Zhang, Da, Marco Springmann, and Valerie J. Karplus. “Equity and Emissions Trading in China." Climatic Change 134.1-2 (2016): 131-146.

As Published: http://dx.doi.org/10.1007/s10584-015-1516-x

Publisher: Springer Netherlands

Persistent URL: http://hdl.handle.net/1721.1/106478

Version: Author's final manuscript: final author's manuscript post peer review, without publisher's formatting or copy editing

Terms of use: Creative Commons Attribution-Noncommercial-Share Alike 


\title{
Equity and emissions trading in China
}

\author{
Da Zhang ${ }^{1,2}$ • Marco Springmann ${ }^{3,4}$. \\ Valerie J. Karplus ${ }^{2,5}$
}

Received: 30 December 2013 / Accepted: 20 September 2015 /Published online: 21 October 2015

(C) Springer Science+Business Media Dordrecht 2015

\begin{abstract}
China has embarked on an ambitious pathway for establishing a national carbon market in the next 5-10 years. In this study, we analyze the distributional aspects of a Chinese emissions-trading scheme from ethical, economic, and stated-preference perspectives. We focus on the role of emissions permit allocation and first show how specific equity principles can be incorporated into the design of potential allocation schemes. We then assess the economic and distributional impacts of those allocation schemes using a computable general equilibrium model with regional detail for the Chinese economy. Finally, we conduct a survey among Chinese climate-policy experts on the basis of the simulated model impacts. The survey participants indicate a relative preference for allocation schemes that put less emissionsreduction burden on the western provinces, a medium burden on the central provinces, and a high burden on the eastern provinces. Most participants show strong support for allocating emissions permits based on consumption-based emissions responsibilities.
\end{abstract}

\section{Introduction}

Reducing the anthropogenic emissions of greenhouse gases (GHGs) linked to climate change is a major challenge for international governance. China surpassed the United States in 2007 to

Electronic supplementary material The online version of this article (doi:10.1007/s10584-015-1516-x) contains supplementary material, which is available to authorized users.

Marco Springmann

marco.springmann@uni-oldenburg.de; marco.springmann@dph.ox.ac.uk

1 Institute of Energy, Environment and Economy, Tsinghua University, Beijing, China

2 Joint Program of the Science and Policy of Global Change, Massachusetts Institute of Technology, Cambridge, MA, USA

3 Department of Economics, University of Oldenburg, 26111 Oldenburg, Germany

4 Present address: Oxford Martin Programme on the Future of Food, Nuffield Department of Population Health, University of Oxford, Old Road Campus, Headington, Oxford OX3 7LF, UK

5 Sloan School of Management, Massachusetts Institute of Technology, Cambridge, MA, USA 
become the world's largest emitter of carbon dioxide $\left(\mathrm{CO}_{2}\right)$ (IEA 2007; MNP 2007) and has faced increasing international pressure to adopt stringent emissions-reduction commitments. In international negotiations China has pledged to reduce its carbon intensity, i.e., $\mathrm{CO}_{2}$ emissions per unit of gross domestic product (GDP) by 40-45\% from 2005 levels by 2020 (NRDC 2009).

China's Twelfth Five-Year Plan for economic and social development (2011-2015) has integrated part of its international commitment into binding national policy. It sets forth the aim to reduce China's carbon intensity by $17 \%$ from 2011 to 2015 and lays out plans to gradually develop a carbon trading market. In 2011, the National Development and Reform Commission of China initiated the development of seven regional carbon trading pilots in five cities (Beijing, Tianjin, Shanghai, Chongqing, Shenzhen) and two provinces (Guangdong, Hubei). The pilots are expected to become operational in 2013 and inform the design of a national emissions trading system to be announced in China's Thirteenth Five-Year Plan (2016-2020).

A national emissions trading system (ETS) has several well-studied advantages over a regional allocation of emissions targets. First, an ETS attains economic efficiency by incentivizing emissions reductions where they are cheapest. By contrast, regionally constrained emissions limits reduce abatement flexibility, leading to equal or greater welfare losses (see, e.g., Tietenberg 2006; and Zhang et al. 2013, for an application to the Chinese context). Second, an ETS attains economic efficiency irrespective of the initial allocation of emissions permits (Coase 1960; Montgomery 1972; Rose and Tietenberg 1993). Thus, efficiency and distributional (equity) objectives can be addressed separately in an ETS. ${ }^{1}$

Distributional issues have been a major concern for China's policy makers in recent years. Pronounced differences exist between the developed eastern-coastal provinces and the less developed central and western provinces (Keidel 2007). Currently, the per-capita GDP in the inland regions is less than half of that in the coastal regions on aggregate (Fan et al. 2011) and the differences between individual provinces and municipalities can reach up to a factor of ten (National Statistics Bureau of China 2008). To a large extent, preferential policy treatment of coastal regions during China's reform period in the late 1970s explains the existing regional economic differences (Démurger et al. 2002). However, more recent regional development strategies have put increased focus on reducing regional disparities (Chen and Zheng 2008) ${ }^{2}$ and the importance of promoting a more balanced regional development has continued to feature prominently in the Eleventh and Twelfth Five-Year Plans for economic and social development (2006-2010; 2011-2015).

In this study, we analyze the distributional aspects that are inherent in the design of a national emissions trading system. We focus on the different design options for allocating emissions permits to China's provinces and the potential economic impacts that result. Although some ETS designs foresee a complete auctioning of emissions permits, most schemes implemented to date have featured an initial allocation of permits to ease the economic impacts on participating regions and industries (Hood 2010). Opting for a specific allocation of emissions permits offers a means of balancing the regional economic impacts of an ETS and at the same time addressing issues of equity and distributional justice inherent in environmental policy making (Grubb et al. 1992; Kverndokk 1995).

This study takes a three-part approach to analyze the distributional aspects of a national ETS in China. First, we construct a range of permit allocation schemes based on underlying ethical frameworks. This part builds on earlier studies on the international burden-sharing of

\footnotetext{
${ }^{1}$ The trade in emissions permits allows emissions to be reduced at least cost, while the initial allocation of emissions permits determines the regional distribution of this cost burden.

2 Policies in that regard are e.g., the "Western development strategy" and the "Rise of central China strategy" in the 1990 s and 2000 s.
} 
emissions reductions (see, e.g., Ringius et al. 2002; Kverndokk and Rose 2008), but adapts the concepts discussed on the international level for the Chinese context.

Second, we analyze the potential economic impacts of different permit allocation schemes by using an interregional energy-economic model of the Chinese economy that separately represents the nation's 30 provinces. This part builds on an earlier assessment of a future ETS in China (Zhang et al. 2013) by explicitly considering different permit allocation schemes. By simulating the regional economic impacts of different allocation schemes in a future ETS, we also go beyond earlier studies which focused on the regional allocation of emissions-intensity reductions among China's provinces without considering their economic impacts or interactions within an ETS (Wei et al. 2011; Yi et al. 2011).

Third, we juxtapose the simulation results with insights based on an ETS survey conducted among Chinese research teams working on domestic climate policy analysis in China. The survey is intended to scope the views on the interregional distribution of burden in a future ETS in China and elicit the preferences for the specific permit allocation schemes analyzed in this study. Our study contributes insights at the regional level, which carries unique importance in China given the heterogeneity of its provinces, distinguishing it from previous studies focused on burden-sharing across nations (Lange et al. 2007, 2010). The three parts of the analysis are described below, followed by an integrated discussion of its implications.

\section{Permit allocation and equity criteria}

Equity considerations are implicit in any approach aimed at distributing the burden of climate change (or the entitlements to emit). They indicate what a person perceives as fair or just (normative perspective). They are also frequently used in international negotiations on climate change (positive perspective), e.g., in the form of "common but differentiated responsibilities" laid out by the United Nations Convention on Climate Change (UNFCCC, 1992, Art.3.1), or the polluter-pays principle endorsed by the Organisation for Economic Co-Operation and Development (OECD 1989).

There exist various categorizations of equity principles. For example, Kverndokk and Rose (2008) group equity principles into allocation-based, outcome-based, and process-based. This study focusses on allocation-based and outcome-based approaches that inform the initial and final allocation of emissions permits, respectively. Table 1 provides an overview of the equity criteria selected for this study. Most of the criteria selected have become canonical (see Kverndokk and Rose 2008, for a detailed review) - those include principles of sovereignty, egalitarian, polluter pays, ability to pay, horizontal, and vertical.

We supplement the canonical equity criteria by three other criteria which are relevant for the Chinese context. We consider two criteria based on emissions intensity, the environmental reward and environmental subsidy criteria (see, e.g., Eyckmans and Finus 2004), due to China's focus on emissions intensity as a policy target. We also add a consumer-pays criterion to account for the significant regional separation that exists within China between production and consumption activities and their associated $\mathrm{CO}_{2}$ emissions (Meng et al. 2011; Guo et al. 2012; Feng et al. 2013; Springmann et al. 2015).

In real decision-making processes, multiple objectives may need to be taken into account, something which would call for combining several equity principles into one allocation scheme (see, e.g., Bear et al., 2008; Raupach et al. 2014). In the main text, we focus on individual principles to illustrate their qualitative differences, but we explore some of the potential combinations in a dedicated sensitivity analysis. 
Table 1 Overview of various equity criteria, their definition, potential references bases, and the operational rules that follow. Scenario abbreviations are listed for further reference in the model and results sections. For detailed discussions on the equity criteria, see e.g., Rose et al. (1998), Kverndokk and Rose (2008), Ringius et al. (2002), and Eyckmans and Finus (2006)

\begin{tabular}{|c|c|c|c|c|}
\hline Criterion & Basic definition & Reference base & Operational rule & Scenario \\
\hline \multicolumn{5}{|l|}{ Allocation-Based } \\
\hline Sovereignty & $\begin{array}{l}\text { All regions have an equal right to } \\
\text { pollute and to be protected from } \\
\text { pollution. }\end{array}$ & $\begin{array}{l}\text { territorial } \\
\text { emissions }\end{array}$ & $\begin{array}{l}\text { Distribute permits } \\
\text { in proportion } \\
\text { to emissions. }\end{array}$ & SOV \\
\hline Polluter pays & $\begin{array}{l}\text { The producers of goods should be } \\
\text { held responsible for the pollution } \\
\text { generated in the process. }\end{array}$ & $\begin{array}{l}\text { territorial } \\
\text { emissions }\end{array}$ & $\begin{array}{l}\text { Distribute permits } \\
\text { inversely to } \\
\text { emissions. }\end{array}$ & PPP \\
\hline Consumer pays & $\begin{array}{l}\text { The consumer of goods should be } \\
\text { held responsible for the pollution } \\
\text { generated in the process. }\end{array}$ & $\begin{array}{l}\text { consumption-based } \\
\text { emissions }\end{array}$ & $\begin{array}{l}\text { Distribute permits } \\
\text { inversely to } \\
\text { emissions. }\end{array}$ & CPP \\
\hline Egalitarian & $\begin{array}{l}\text { All people have an equal right } \\
\text { to pollute and to be protected } \\
\text { from pollution. }\end{array}$ & population & $\begin{array}{l}\text { Distribute permits in } \\
\text { proportion to } \\
\text { population. }\end{array}$ & EGA \\
\hline Ability to pay & $\begin{array}{l}\text { Greater burden should be } \\
\text { shouldered by those with } \\
\text { higher economic resources. }\end{array}$ & inverse GDP & $\begin{array}{l}\text { Distribute permits } \\
\text { inversely to } \\
\text { per-capita GDP. }\end{array}$ & $\mathrm{ABT}$ \\
\hline $\begin{array}{l}\text { Environmental } \\
\text { reward }\end{array}$ & $\begin{array}{l}\text { Greater burden should be } \\
\text { shouldered by those with higher } \\
\text { potential for reducing emissions. }\end{array}$ & $\begin{array}{l}\text { inverse emissions } \\
\text { intensity }\end{array}$ & $\begin{array}{l}\text { Distribute permits } \\
\text { inversely to } \\
\text { emissions intensity. }\end{array}$ & ERE \\
\hline $\begin{array}{l}\text { Environmental } \\
\text { subsidy }\end{array}$ & $\begin{array}{l}\text { The regions with the greatest } \\
\text { potential for reducing emissions } \\
\text { should be supported. }\end{array}$ & emissions intensity & $\begin{array}{l}\text { Distribute permits } \\
\text { in proportion to } \\
\text { emissions intensity. }\end{array}$ & ESU \\
\hline \multicolumn{5}{|l|}{ Outcome-Based } \\
\hline Horizontal & $\begin{array}{l}\text { Regions with similar economic } \\
\text { circumstances should bear } \\
\text { similar burden. }\end{array}$ & welfare & $\begin{array}{l}\text { Equalize welfare } \\
\text { changes across } \\
\text { regions. }\end{array}$ & EQU \\
\hline Vertical & $\begin{array}{l}\text { Regions with higher per-capita } \\
\text { GDP should bear a greater } \\
\text { burden. }\end{array}$ & welfare & $\begin{array}{l}\text { Distribute net welfare } \\
\text { losses in proportion } \\
\text { to per-capita GDP. }\end{array}$ & PRG \\
\hline
\end{tabular}

In the following, we will focus on specific allocation schemes emerging from the different equity principles. In order to use an equity principle to allocate emissions permits, one has to specify its reference base. A reference base, such as emissions or population, transforms an equity principle into an operational rule, but has no ethical content by itself (Rose et al. 1998). The reference bases applied to the equity criteria selected in this study are emissions (territorial and consumption-based), GDP, emissions intensity (i.e., emissions per unit of GDP), and population.

\subsection{Database}

For specifying the equity criteria, reference bases, and the associated allocation schemes for the Chinese context, we employ a comprehensive database of economic activity, energy use, and associated $\mathrm{CO}_{2}$ emissions for China's provinces compiled by Zhang et al. (2013). The data is based on China's national input-output table and the full set of China's provincial input-output tables published in 2007 (National Statistics Bureau of China 2011). The provincial input-output data for China specifies benchmark economic accounts for 30 provinces in China (Tibet is not 
included due to a lack of data and the small scale of its economic activities). Energy use is based on the 2007 China Energy Statistical Yearbook and emissions totals are quantified using fuelspecific $\mathrm{CO}_{2}$ emissions factors (National Statistics Bureau of China 2008). Zhang et al. (2013) provide further details on the method used for balancing and combining the data sets.

For ease of presentation, we group China's provinces into eastern, central, and western ones according to the three economic zones defined in China's Seventh Five-Year Plan (State Council of China 1986; Feng et al. 2012). ${ }^{3}$ Supplementary Figure S1 provides the details of this regional aggregation. ${ }^{4}$ The eastern provinces belong to the most economically developed areas with high levels of industrialization and rapid growth in international trade. The central provinces are less developed than the eastern provinces, but they have well-established infrastructures and abundant natural resources, such as coal, oil, and metal ores. The western provinces are the least developed ones, but they possess abundant coal, oil and natural gas reserves.

Figure 1 shows the regional distribution of the indicators used as references bases for this study's allocation schemes ( $\mathrm{CO}_{2}$ emissions, GDP, emissions intensity, and population). In general, population, economic activity, and $\mathrm{CO}_{2}$ emissions are most concentrated in the eastern provinces, less concentrated in the central provinces, and least concentrated in the western provinces. Consumption-based emissions exacerbate that trend, because the eastern provinces consume more goods and associated $\mathrm{CO}_{2}$ emissions than they produce (see Supplementary Figure S2). The distribution of emissions intensity shows an opposite trend, i.e., lower emissions intensity in the eastern provinces and higher emissions intensity in the central and western provinces, which reflects differences in technological progress and industrial composition.

\subsection{Permit allocation across China's provinces}

We follow Rose et al. (1998) in their general methodology of mathematically specifying different permit-allocation schemes. To obtain the allocation of emissions permits for region $r$ and allocation scenario $i\left(E_{r}^{i}\right)$, we distribute a national emissions target $\left(\overline{\mathrm{CO}_{2}}\right)$ among Chinese provinces in proportion to their share with respect to the chosen reference base $\left(b_{r}^{i}\right)$ :

$$
E_{r}^{i}=\frac{b_{r}^{i}}{\sum_{s} b_{s}^{i}} \overline{C O_{2}}
$$

For example, the egalitarian scenario allocates emissions permits in proportion to a region's population divided by the total population and multiplied by the national emissions target. To specify the consumer-pays criterion, we calculate consumption-based emissions using a multiregional input-output approach that accounts for the emissions embodied in China's interregional trade (see Springmann et al. 2015). ${ }^{5}$

\footnotetext{
${ }^{3}$ Following Feng et al. (2012), we group Guangxi as a western province due to its economic similarities with western provinces. Although Inner Mongolia is sometimes also grouped as a western province, we group it as a central province, which is in line with its economic characteristics and with the grouping described by the State Council of China (1986).

${ }^{4}$ All supplementary material are contained in an online resource, which is made available on the journal's website.

${ }^{5}$ The outcome-based allocation scenarios (vertical and horizontal) depart from this methodology because they impose constraints on the outcome of economic model simulations. The horizontal EQU scenario equalizes the proportional welfare impacts across all provinces and the vertical PRG scenario distributes welfare losses in proportion to per-capita GDP. The details of the economic model and the model simulations are described in Section 3.
} 


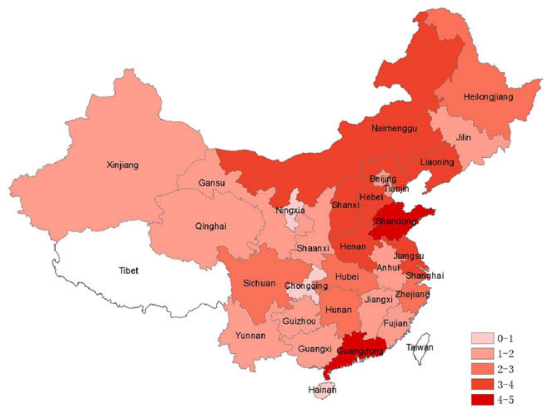

(a)

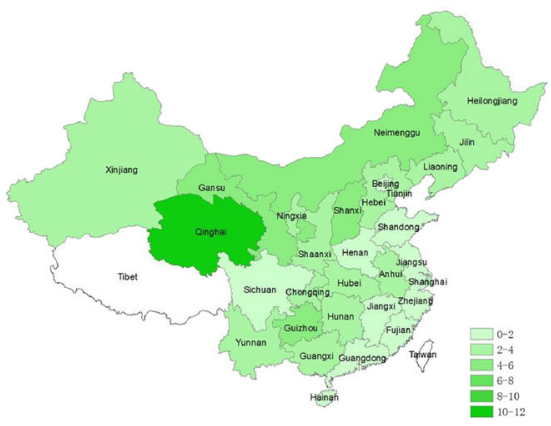

(c)

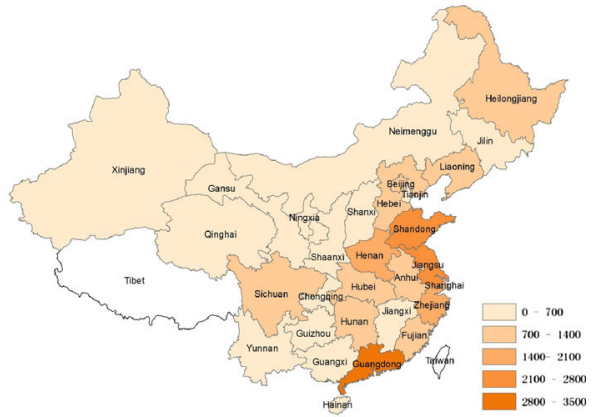

(b)

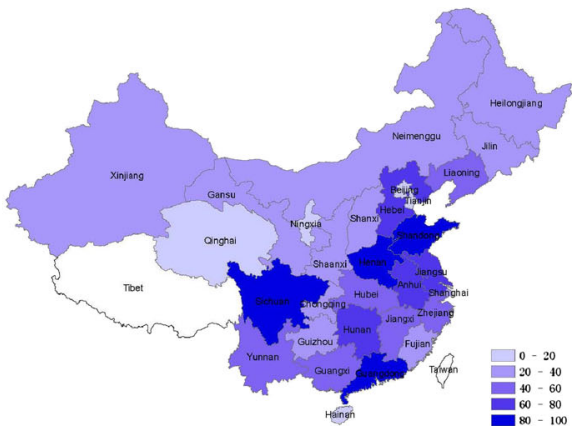

(d)

Fig. 1 Regional distribution of a CO2 emission (100 million tons), b GDP (billion Yuan), c CO2 emission intensity (ton/10,000 Yuan), and d population (million) across China's provinces in 2007. Tibet is not included due to data availability

The basis for each allocation scenario is a stylized national emissions trading system in which the national emissions cap is set $17.7 \%$ below benchmark emissions. As of writing, there is little information about how much a national ETS would contribute to China's overall emissions intensity target and how stringent the absolute emissions trajectory of a future ETS would be. In absence of such information, we have chosen to adopt an absolute emissions target that, in our static energy-economic model, results in similar emissions intensity reductions as aimed for in China's Twelfth Five-Year Plan (2011-2015). Absolute emissions targets can be expected to differ in a dynamic setting that takes into account projections of economic growth, but their exact value is less relevant for the focus of our study, which is to analyze the distributional impacts of different permit allocation schemes. We test this assertion by conducting a sensitivity analysis with higher and lower emissions targets.

Finally, we constrain the permit allocation such that no province can be allocated more than its baseline emissions. The purpose of this "stand-alone rule" (Lange et al. 2007) is to avoid undermining emissions-reduction efforts in overallocated provinces, which may be viewed as unacceptable by constrained provinces. Supplementary Section S3 shows that overallocation would also lead to disproportional wealth transfers (in terms of permit revenues).

Figure 2 displays the regional allocation of emissions permits for the allocation scenarios considered (Supplementary Table S4 lists the permit allocation for each province). Several scenarios exhibit similar allocative characteristics (after each provinces' permit allocation has been constrained to not exceed its benchmark emissions). The ERE and SOV scenarios allocate most emissions 


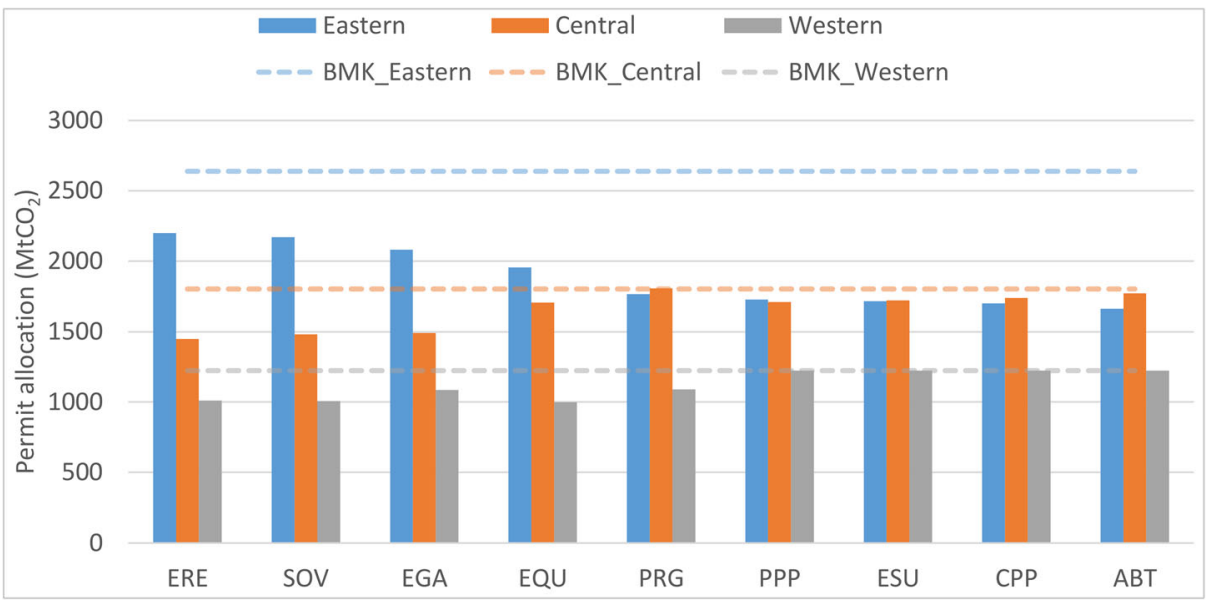

Fig. 2 Regional permit allocation to China's eastern, central, and western provinces for the different allocation scenarios described in Table 1. The dashed horizontal lines indicate the aggregated benchmark emissions for the eastern, central, and western provinces

permits to the eastern provinces because their allocation methods reward low emissions intensity (ERE) and high emissions (SOV). The central provinces are allocated about a third less emissions permits than the eastern provinces, and the western provinces about half. In line with the allocation method of the SOV scenario, each province is allocated the same proportional $17.7 \%$ reduction of emissions permits compared to current benchmark emissions.

Going from the EGA scenario to the ABT scenario, fewer emissions permits are allocated to the eastern provinces and more to the central and western ones. The shift in permit allocation is small in the EGA scenario as the eastern provinces have a greater population on aggregate than the central and western ones. However, the proportional cutback between benchmark emissions and emissionspermit allocation for the eastern provinces increases to 33-35\% in the PRG, PPP, ESU, CPP, and ABT scenarios. This is in line with the scenarios' allocation methods, which allot more emissions permits to the provinces with low emissions (PPP), high emissions intensities (ESU), low consumption (CPP), and low per-capita GDP (ABT, PRG), all of which are concentrated more in the center and west than in the east. As a result of the stand-alone rule, the PPP, ESU, CPP, and ABT scenarios allocate permits in proportion to benchmark emissions to many western provinces, while permit allocations in the PRG scenario approach benchmark levels in some central provinces.

\section{Economic impacts of different permit allocations}

We now turn to simulate the economic and distributional effects of allocating emissions permits in a Chinese ETS according to the scenarios described above. For this analysis, we use an energy-economic model with regional detail for the Chinese economy (see Zhang et al. 2013). We provide a short model description followed by a discussion of the results.

\subsection{Energy-economic model}

The energy-economic model is a static multi-regional multi-sector computable general equilibrium model based on optimizing behavior of economic agents. Consumers maximize 
welfare subject to budget constraints and producers combine intermediate inputs and primary factors at least cost to produce output. Energy resources are included as primary factors and their use is associated with the emission of carbon dioxide $\left(\mathrm{CO}_{2}\right)$. The production of energy and other goods is described by nested constant-elasticity-of-substitution (CES) production functions which specify the input composition and substitution possibilities among inputs. Inputs into production include labor, capital, natural resources, and intermediate inputs. Supplementary Section S5 contains further details on the model's nesting structure and its formulation.

The model is calibrated to a comprehensive energy-economic data set which includes a consistent representation of energy markets in physical units, as well as detailed economic accounts for the year 2007. The dataset is global, but includes regional detail for China's provinces. The global data comes from the database version 8 of the Global Trade Analysis Project (GTAP, Narayanan et al. 2012). Results for the rest of the world are aggregated at the level of three international regions (Europe, USA, and the rest of the world) to capture the international market impacts of distributional changes within China. The data for China is based on the country's national input-output table and the full set of provincial input-output tables published in 2007 (National Information Center of China, 2011) as described in Section 2. We resolve six energy sectors and 10 non-energy composites. ${ }^{6}$ Elasticities of substitution are adopted from the GTAP 8 database, as well as from the MIT Emissions Prediction and Policy Analysis (EPPA) model (Paltsev et al. 2005).

Although we calibrate our energy-economic model to the latest available data, we note that the model results are best be seen as illustrative of the general trends and relative trade-offs between the ETS allocation scenarios. In line with our distributional focus, we abstract from dynamic aspects that describe future trajectories of emissions and economic development which would be important for concrete forecasts of China's future climate policies. In contrast, the relative changes across the different allocation scenarios can be seen as sufficiently robust under a wide range of potential ETS designs (see the sensitivity analysis contained in Supplementary Section S9 and Zhang et al. 2013, who analyze the effects of market distortions and parameter assumptions using the same energy-economic model applied here).

\subsection{Permit transfers and welfare impacts}

In an ETS, the trade in emissions permits results in the equalization of marginal abatement costs across provinces leading to a cost-efficient distribution of emissions reductions and a single price of carbon, which, in the scenarios analyzed here, amounts to $15 \mathrm{USD} / \mathrm{tCO}_{2}$. Of interest under each scenario is the final distribution of emissions reductions, the transfer of permits supporting this distribution, as well as the resulting changes in welfare levels for the different ETS allocation scenarios considered.

All national ETS scenarios result in a common cost-effective distribution of emissions reductions. Although the absolute emissions reductions are similar for the eastern, central, and western provinces (about $330 \mathrm{MtCO}_{2}$ on average), the western provinces reduce emissions the most on a percentage basis - by $27 \%$ on aggregate - followed by the central and eastern

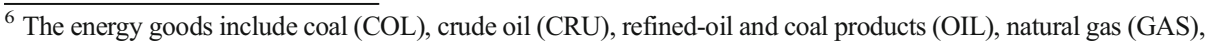
gas manufacture and distribution (GDT), and electricity (ELE); the non-energy sectors include agriculture (AGR), minerals mining (OMN), light industries (LID), energy-intensive industries (EID), transport equipment (TME), other manufacturing industries (OID), water (WTR), trade (TRD), transport (TRP), other service industry $(\mathrm{OTH})$.
} 
provinces which reduce their emissions by 20 and $12 \%$, respectively (see Supplementary Table S6). Underlying this cost-effective distribution of emissions reductions are regional differences in marginal abatement costs, which are highest in the eastern provinces and lowest in the western ones - the distribution of emissions intensities is indicative of those differences (see Fig. 1).

The distribution of emissions reductions can differ significantly from the initial distribution of emissions permits in each scenario. The differences are especially pronounced in the PPP, ESU, CPP, and ABT scenarios in which most of the western provinces are allocated their benchmark emissions and the eastern provinces are allocated $35 \%$ fewer permits than their benchmark emissions on aggregate.

Supplementary Section S7 details the permit (and associated financial) transfers that occur to achieve the distribution of emissions reductions in each ETS scenario. The permit transfers emerge as the difference between the cost-efficient distribution of emissions reductions and the emissions permits allocated in each scenario. In each scenario, the eastern provinces are, on aggregate, net buyers of emissions permits, while the central and western provinces are net sellers. The permit and revenue transfers increase from about 130-160 MtCO2 for USD 1.92.3 billion in the ERE and SOV scenarios to 560-660 MtCO2 for USD 8.3-9.8 billion in the PRG, PPP, ESU, CPP, and ABT scenarios, which is in line with the reduction in the amount of emissions permits allocated to the eastern provinces in those scenarios.

Figure 3 shows the regional welfare impacts in terms of equivalent variation of income for the different ETS allocation scenarios (provincial-level welfare impacts are listed in Supplementary Table S8). Each ETS scenario results in a cost-efficient distribution of emissions reductions with the same national welfare impact. However, regional welfare impacts differ according to each province's permit allocation, marginal abatement costs, and transfer of permit revenues. As a consequence, the ERE, SOV, and EGA scenarios exhibit low welfare losses for the eastern provinces, but high losses for the central ones (as those are particularly reliant on fossil-fuel production), while the PRG, PPP, ESU, CPP, and ABT scenarios show

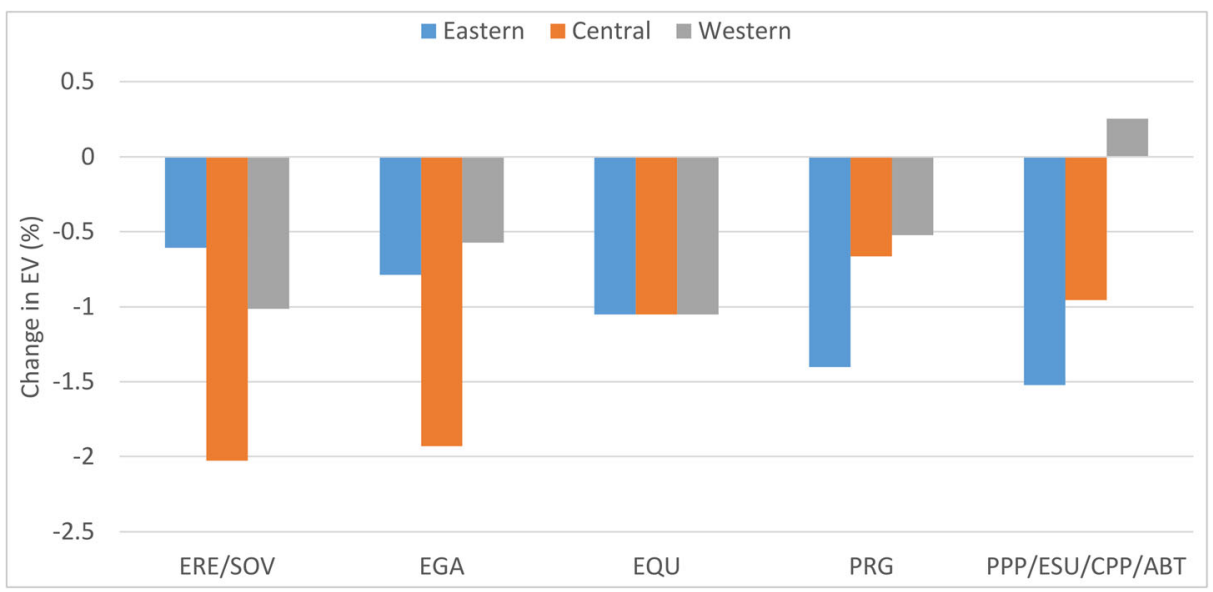

Fig. 3 Regional distribution of welfare impacts in terms of equivalent variation of income (EV) for the different allocation scenario. The ERE and SOV scenarios and the PPP, ESU, CPP, ABT are associated with similar welfare impacts; we group those scenarios together (by taking the average values) for ease of presentation. The figure serves as basis for the survey described in section 4 
low welfare losses or even gains for the western provinces, but greater losses for the eastern ones. By definition, the EQU scenario yields a proportionally equal burden for all provinces.

We conducted two sensitivity analysis to complement the main results. A sensitivity analysis contained in Supplementary Section S9 shows that the relative trade-offs between allocation schemes are robust with respect to changes in the stringency of the overall emissions target and to changes in key model parameters that govern the substitutability of energy inputs with other goods and of goods between provinces. A sensitivity analysis contained in Supplementary Section S10 shows that adopting two mixed allocation schemes (PPP + ABT, SOV+EGA) that have been discussed in the literature (Baer et al. 2008; Raupach et al. 2014) results in similar permit allocation and welfare impacts as the individual allocation schemes, something that is largely due to the "stand-alone rule," which rules out overallocation and leads to convergence among the individual allocation schemes.

\section{Choosing among allocation schemes}

The preceding analysis provided an overview of the distribution of economic impacts under a wide range of allocation schemes applied to the Chinese context. Each allocation scheme is supported by a specific equity criterion and therefore justifiable from a particular ethical position. This complicates the selection and recommendation of a particular allocation rule to policymakers. Instead of assuming what equity rule would be most compelling in China, we conducted a survey to scope the views on the different allocation schemes and, more generally, on the importance of the interregional distribution of burden in a future ETS in China.

\subsection{Survey overview}

The survey was distributed among Chinese research groups involved in the analysis and design of climate policy in China. In general, input from expert research groups is very important in China's policy process (Cao 2004). In the process of establishing pilot emissions trading schemes as part of the Twelfth Five-Year Plan, the government is regularly seeking input from research groups on the design of a future emissions trading system, and the policy advice provided to the government has, in many instances, been based on model assessments. We therefore focus on research groups with modeling capacity in national climate policies as target group for our survey.

The survey was distributed at two instances which ensured the representation of relevant research teams in our focus group (see Supplementary Section S12). We received 44 responses which constitutes a good response rate given the target group. While we cannot claim that our sample is representative of specific population groups (see Supplementary Table S12.2), it can provide insights into the relative merits of alternative burden-sharing scenarios according to scholars involved in China's climate policy design.

The questionnaire administered in the survey was structured into four parts (see Supplementary Information 2). The first elicited the participants' general views on the importance of distributional issues (equity) and of efficiency. The second part asked the participants to distribute the burden of emissions reduction among China's regions (eastern, central, western) and express their opinion on different burden-sharing rules. The third part presented participants with the model outcomes discussed in the last section (Fig. 5) and asked for their preferred outcome and unacceptable outcomes. The welfare impacts were first 
presented without scenario labels and then with scenario labels and brief descriptions of the equity criteria supporting each allocation scenario. The intention behind this two-stage approach was to elicit participants' distributional preferences with and without the ethical framing. The participants were given the option to change their preferences based on the information provided. Finally, the questionnaire asked for some background information, such as age, affiliation, and regions of origin and residence.

\subsection{Survey results}

Over $80 \%$ of the respondents declare that they are concerned with the way the economic burden of greenhouse gas reduction is distributed among China's provinces and more than half think that fairly distributing the burden of emissions reduction has the same importance as reducing emissions at least cost (see Supplementary Table S13). When prompted to distribute the burden of emissions reduction among China's regions, assuming that the distribution of burden does not increase overall costs, most respondents would put a medium-high to high burden on the eastern provinces ( $89 \%$ ), a medium burden on the central provinces $(66 \%)$, and a low to medium-low burden on the western provinces (75\%). The associated distribution of frequencies is shown in Fig. 4.

Figure 5 details the respondents' preferences for specific allocation schemes. When presented with the simulated welfare impacts of the specific unlabeled burden-sharing criteria considered in this study, $41 \%$ chose the progressive (PRG) scenario as their most preferred one, followed by the aggregate of polluter pays, consumer pays, ability to pay, and environmental subsidy (PPP/CPP/ABT/ESU) which was chosen by $27 \%$; the egalitarian (EGA) scenario was chosen by the least (7\%). When asked which of the different outcomes would be unacceptable (multiple choices were possible here), $57 \%$ of the respondents indicated that they would not be willing to accept the sovereignty and environmental reward (SOV/ERE) scenarios, $34 \%$ would not accept the equal impact (EQU) scenario, and $30 \%$ would not accept the egalitarian (EGA) scenario.

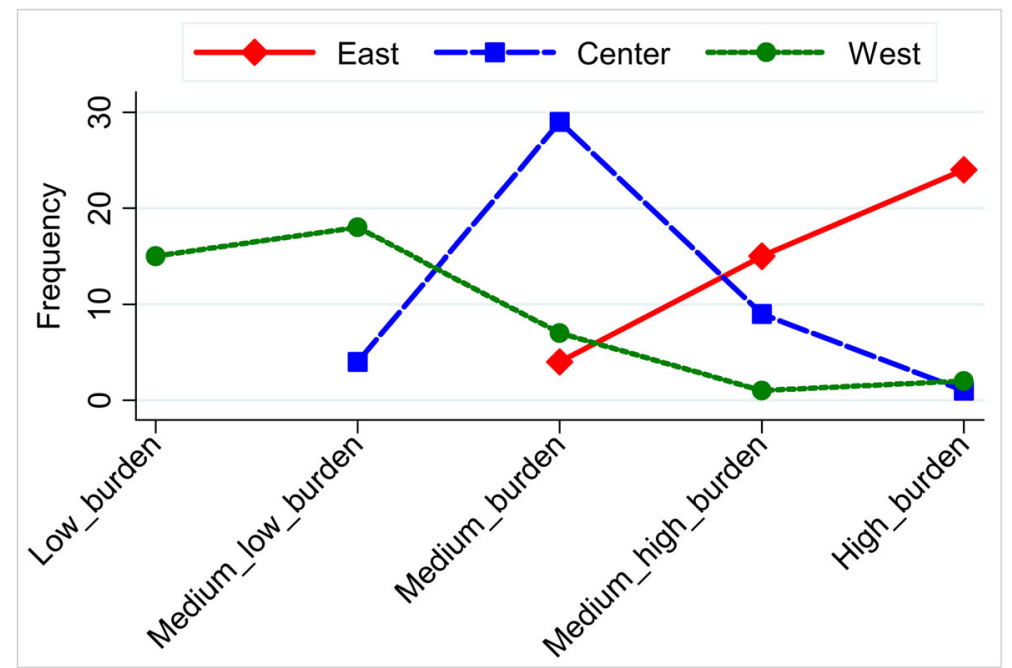

Fig. 4 Respondents' preferences for the regional distribution of emissions-reduction burden among the eastern, central, and western provinces 

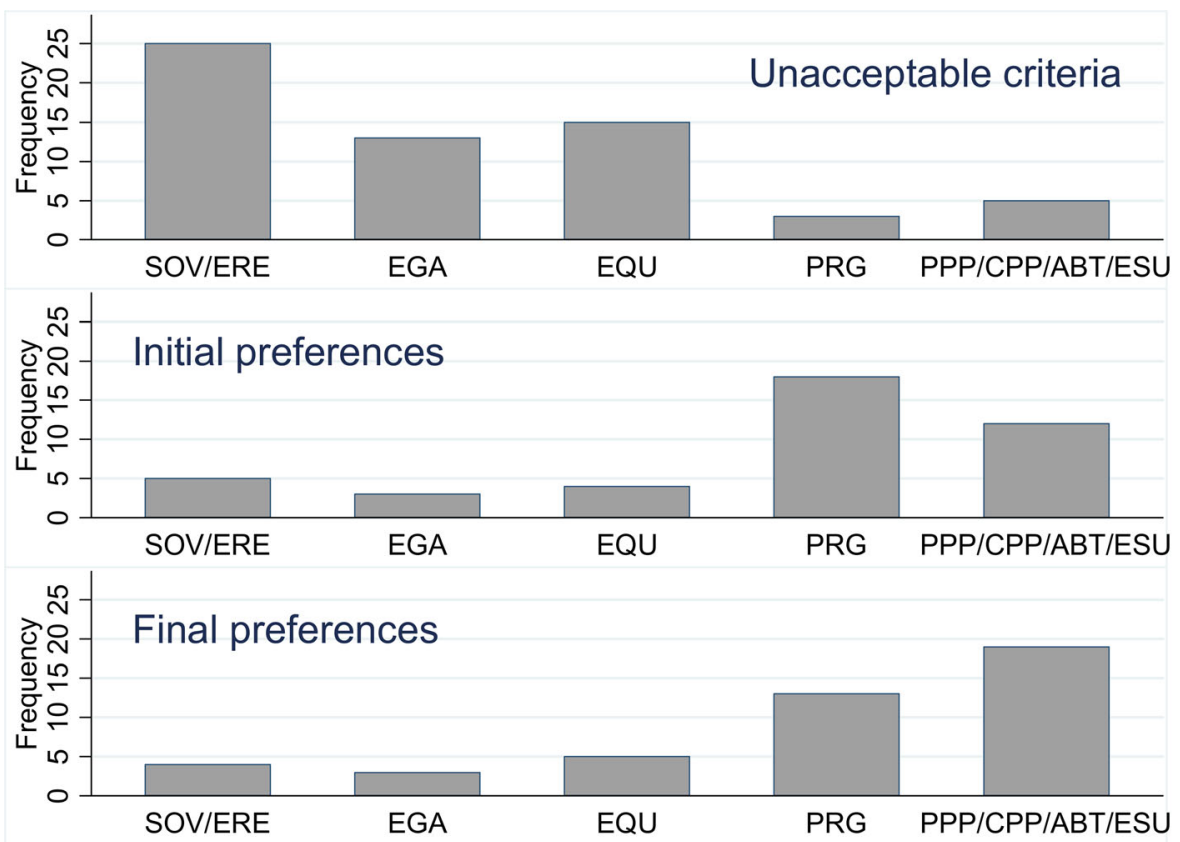

Fig. 5 Respondents' preference for the specific allocation schemes considered in this study. The initial preferences followed the presentation of unlabeled welfare outcomes, the final preferences the presentation of labeled outcomes and scenario descriptions, and the unacceptable criteria indicate the schemes the respondents found unacceptable when first presented (with multiple choices possible)

When the burden-sharing scenarios were identified, a third of the respondents $(32 \%)$ changed their preference, mostly from the PRG scenario to the PPP/CPP/ABT/ESU one. While most respondents did not provide a reason for that change, the ones that did noted that the aggregate $\mathrm{PPP} / \mathrm{CPP} / \mathrm{ABT} / \mathrm{ESU}$ scenario is more comprehensive and that it considers both responsibility and capacity. The final distribution of preferences (depicted in the lower panel of Fig. 5) shows that $43 \%$ would prefer the PPP/CPP/ABT/ESU scenario, $30 \%$ the PRG scenario, $11 \%$ the EQU scenario, $9 \%$ the SOV/ERE scenario, and $7 \%$ the EGA scenario.

When asked about their agreement on the individual burden-sharing criteria in the PPP/ $\mathrm{CPP} / \mathrm{ABT} / \mathrm{ESU}$ group, the respondents indicated strongest agreement with the CPP criterion, followed by the PPP, ESU, and ABT scenarios (see Supplementary Figure S13).

\subsection{Discussion of survey results}

Interestingly, we find that most respondents favor a higher burden on the east and lower burden on the center and west, as well as a preference for allocation schemes which are supported by multiple criteria. A stratification of responses by regions of origin and residence shows that respondents are not markedly influenced by their former or current locations (Supplementary Section S14). This is opposed to findings from surveys on burden-sharing on the international level (Lange et al. 2007, 2010). One reason for the difference may be that environmental (including climate) policy issues are traditionally addressed at the central level in China (Wang 2013; Kostka 2015), and balancing impacts across regions is often an important consideration 
(Wei et al., 2011; Yi et al. 2011). Thus, the experts in our target group may adopt a regionally more balanced view on distributional and efficiency issues than lay persons or representatives from affected industries and policy experts from other countries.

The ideologies of collectivism and centralism have a long tradition in China and offer a potential explanation for the stated differences in views. Rooted in Chinese philosophy, collectivism and centralism are components of the moral education by the Communist Party (Law 2006; Lee and Ho 2006), and as a result, affect both politics (Lai 2002) and daily business (Chen et al. 1997). Concrete representations of collectivism are the concepts of "balancing regional development" and "rich people help the poor", which have been adopted by policy makers since the 1990s as a means of addressing China's regional imbalances. Given the increasingly prominent role of the central government in environmental policy decisions, previous scholars have noted how environmental NGOs and civil society in China tend to stay more in line with the directions from the central government compared to their western counterparts (Ho 2001)."

Notwithstanding, there are several caveats to bear in mind when interpreting the survey results. First, we cannot rule out occasional misinterpretations of survey questions and an impact from framing the questions. ${ }^{7}$ We tried to address this point by providing explanatory paragraphs, bilingual questionnaires, and possibilities for personal feedback. Second, our target group consisted of climate-policy experts and therefore does not represent broader views on desirable distributional outcomes in China. Finally, the survey's regional aggregation into three broad regions may hide some regional differences and the respondents' interests in the impacts for specific provinces.

\section{Conclusion}

China has embarked on an ambitious pathway for establishing a national carbon market in the next 5-10 years. In this study, we have analyzed the distributional aspects of a Chinese ETS from ethical, economic, and stated-preference perspectives. We have focused on the role of emissions permit allocation and showed that a wide range of potential allocation schemes exist, each supported by a specific equity principle. The economic analysis has shown that several allocation schemes exhibit similar distributional characteristics in terms of regional welfare impacts and flows of emissions permits when overallocation is ruled out.

A survey we have conducted among climate-policy researchers in China has indicated a relative preference for those allocation schemes that put less emissions-reduction burden on the western provinces, a medium burden on the central provinces, and a high burden on the eastern provinces. When presented with the specific allocation schemes considered in this study, most respondents preferred the welfare outcome associated with the equity criteria of polluter pays, consumer pays, ability to pay, and ecological subsidy, noting that this combination of criteria is most comprehensive, while at the same time being in line with the respondents' general distributional preferences.

From a fiscal perspective, each allocation scheme would imply significant interregional transfers. In each allocation scheme, the eastern provinces are found to be net buyers of emissions permits, with permit payments to the western and central provinces ranging between USD 2-10 billion depending on the allocation scheme. In comparison, the annual equalization transfer, which was established by the Chinese government in 1995 to ease the widening

\footnotetext{
${ }^{7}$ In particular the EQU (equal welfare losses imposed across all provinces) may not have been well understood by survey respondents, given that it is based on a theoretical construct and not on a tangible indicator or indicators, which have been used to guide the setting of China's energy and climate policy to date.
} 
regional disparities, amounted to about USD 9 billion (74.5 billion Yuan) in 2004 (Shen et al., 2012). The financial transfers associated with an ETS would therefore constitute a significant flow of interregional funds. ${ }^{8}$

From a political perspective, adopting allocation schemes which generate large interregional transfers could be challenging. An analysis of the regional emissions-intensity targets of the China's Twelfth Five-Year Plan has shown that the eastern provinces currently shoulder a relatively modest reduction burden compared to that of the central and western provinces (see Supplementary Section S11 and Springmann et al. 2015). The potentially negative consequences for the eastern provinces in those scenarios that are preferred by most survey participants may hinder adoption given the political and economic influence that those provinces have. However, there may exist room for negotiation between the central government and the provinces on specific allocation schemes, as moving from regional targets to an ETS could significantly reduce overall (national) welfare losses (Zhang et al. 2013).

Although our analysis has focused on the Chinese context, its approach of studying the distributional impacts of regional emissions allocation within a national emissions-trading system has international implications. Balancing economic efficiency with distributional and equity concerns can be expected to play a key role in other emerging carbon markets, in particular in countries with large regional inequalities and uneven economic development, such Brazil, Canada, Chile, Mexico, Turkey, and the USA. While some analyses exist for a selection of those countries (Rose and Zhang 2004; Böhringer et al. 2014), none have elicited the potential preferences that affected groups might have for particular burden sharing schemes, and few have considered an extended set of equity criteria that includes consumption-based responsibilities despite the large fraction of emissions embodied in goods traded within those countries (Caron et al. 2014). By combining economic modeling of a large set of equity criteria with survey techniques, our study represents a more comprehensive analysis than those relying on one method alone. Such multi-method approaches may prove compelling as a way to identify consensus options in the policy design process both in China and in other regions with high degrees of uneven economic development.

Acknowledgments We greatly thank the survey respondents and those who facilitated the distribution of the survey, in particular Prof. Libo Wu at Fudan University. We also thank Dr. John Reilly at MIT and Dr. Cyril Cassisa at Tsinghua University for helpful comments on the survey design. The authors gratefully acknowledge the support of Eni S.p.A., the French Development Agency (AFD), ICF International, and Shell International Limited, founding sponsors of the China Energy and Climate Project, as well as the AXA Research Fund, which is supporting Marco Springmann's doctoral research. We are also grateful for support provided by the Ministry of Science and Technology of China (Grant No. 2012BAC20B07) and Rio Tinto. We further thank the MIT Joint Program on the Science and Policy of Global Change for support through a consortium of industrial sponsors and Federal grants.

\section{References}

Baer P, Fieldman G, Athanasiou T, Kartha S (2008) Greenhouse development rights: towards an equitable framework for global climate policy. Camb Rev Int Aff 21:649-669

\footnotetext{
${ }^{8}$ An added benefit is that the market-based nature of those flows may make them more robust and predictable than budgetary government transfers which have been subject to fluctuation in the past (Shen et al., 2012). However, a market-based scheme also means that the magnitude of the interregional flows will be subject to fluctuations in the carbon price.
} 
Böhringer C, Rivers N, Rutherford TF, Wigle R (2014) Sharing the burden for climate change mitigation in the Canadian Federation. Working Paper No. V-362-14. University of Oldenburg, Department of Economics

Cao C (2004) China's scientific elite. Routledge Studies on China in Transition, Book 21

Caron J, Metcalf GE, Reilly J (2014) The $\mathrm{CO}_{2}$ content of consumption across US regions: a multi-regional inputoutput (MRIO) approach. MIT Joint Program Report 266

Chen CC, Meindl JR, Hunt RG (1997) Testing the effects of vertical and horizontal collectivism: a study of reward allocation preferences in China. J Cross-Cult Psychol 28:44-70

Chen M, Zheng Y (2008) China's regional disparity and its policy responses. China World Econ 16:16-32

Coase RH (1960) The problem of social cost. J Law Econ 3:1-30

Démurger S, Sachs JD, Woo WT, Bao S, Chang G, Mellinger A (2002) Geography, economic policy, and regional development in China. Asian Econ Pap 1:146-197

Eyckmans J, Finus M (2004) An empirical assessment of measures to enhance the success of global climate treaties. Katholieke Universiteit Leuven, Centrum voor Economische Studiën, Energy, Transport and Environment

Fan S, Kanbur R, Zhang X (2011) China's regional disparities: experience and policy. Review of Development Finance 1(1):47-56

Feng K, Davis SJ, Sun L, Li X, Guan D, Liu W, Liu Z, Hubacek K (2013) Outsourcing $\mathrm{CO}_{2}$ within China. PNAS 110(28):11654-11659

Feng K, Siu YL, Guan D, Hubacek K (2012) Analyzing drivers of regional carbon dioxide emissions for China. J Ind Ecol 16(4):600-611

Grubb M, Sebenius J, Magalhaes A, Subak S (1992) Sharing the burden in Confronting climate change: risks, implications and responses. Cambridge University Press, Cambridge, pp 305-322

Guo J, Zhang Z, Meng L (2012) China's provincial $\mathrm{CO}_{2}$ emissions embodied in international and interprovincial trade. Energ Policy 42:486-497

Ho P (2001) Greening without conflict? Environmentalism, NGOs and civil society in China. Dev Chang 42:893-921

Hood C (2010) Reviewing existing and proposed emissions trading systems. IEA Energy Pap.

International Energy Agency (IEA) (2007) World energy outlook 2007: China and India insights. Paris, France

Keidel A (2007) China regional disparities - the causes and impact of regional inequalities in income and wellbeing. Carnegie Endowment for International Peace

Kostka G (2015) Command without control: the case of China's environmental target system. Regul Gov, in press

Kverndokk S (1995) Tradeable $\mathrm{CO}_{2}$ emission permits: initial distribution as a justice problem. Environ Value 4: $129-148$

Kverndokk S, Rose A (2008) Equity and justice in global warming policy. Int Rev Environ Res Econ 2:135-176

Lange A, Vogt C, Ziegler A (2007) On the importance of equity in international climate policy: an empirical analysis. Energ Econ 29:549-562

Lange A, Löschel A, Vogt C, Ziegler A (2010) On the self-interested use of equity in international climate negotiations. Eur Econ Rev 54:359-375

Lai HH (2002) China's western development program: its rationale, implementation, and prospects. Mod China 28:432-466

Law WW (2006) Citizenship, citizenship education, and the state in China in a global age. Camb J Educ 36:597-628

Lee WO, Ho CH (2006) Ideopolitical shifts and changes in moral education policy in China. J Moral Educ 34: 413-431

Meng L, Guo J, Chai J, Zhang Z (2011) China's regional $\mathrm{CO}_{2}$ emissions: characteristics, inter-regional transfer and emission reduction policies. Energ Policy 39(10):6136-6144

MNP (Netherlands Environmental Assessment Agency). (2007) China now No. 1 in $\mathrm{CO}_{2}$ emissions; USA in second position. www.pbl.n1/en/dossiers/Climatechange/moreinfo/ChinanownolinCO2emissionsUSAi nsecondposition. Accessed 29 October 2012.

Montgomery WD (1972) Markets in licenses and efficient pollution control programs. J Econ Theory 5:395-418

Narayanan BG, Aguiar A, McDougall R (eds) (2012) Global trade, assistance, and production: the GTAP 8 data base, Center for Global Trade Analysis, Purdue University

National Statistics Bureau of China (2008) 2007 China energy statistical yearbook

National Statistics Bureau of China (2011) 2007 China regional input-output tables

NRDC (National Resources Defense Council) (2009) From Copenhagen accord to climate action: tracking national commitments to curb global warming. www.nrdc.org/international/copenhagenaccords/. Accessed 29 October 2012

OECD (1989) Recommendation of the council concerning the application of the polluter-pays principle to accidental pollution C(89)88. Organization of Economic Cooperation and Development, Paris

Paltsev S, Reilly JM, Jacoby HD, Eckaus RS, McFarland J, Sarofim M, Asadoorian M, Babiker M (2005) The MIT Emissions Prediction and Policy Analysis (EPPA) model: Version 4, Report No. 125, Joint Program on the Science and Policy of Global Change. Massachusetts Institute of Technology, Cambridge 
Springmann M, Zhang D, Karplus VJ (2015) Consumption-based adjustment of emissions-intensity targets: an economic analysis for China's provinces. Environ Resour Econ 61:615-640

State Council of China (1986) The Seventh Five-Year Plan for national economic and social development of the People's Republic of China, 1986-1990. State Council of China, Beijing

Raupach MR et al (2014) Sharing a quota on cumulative carbon emissions. Nat Clim Chang 4:873-879

Ringius L, Torvanger A, Underdal A (2002) Burden sharing and fairness in international climate policy. Int Environ Agreem-P 2:1-22

Rose A, Stevens B, Edmonds J, Wise M (1998) International equity and differentiation in global warming policy. Environ Resour Econ 12(1):25-51

Rose A, Tietenberg T (1993) An international system of tradeable $\mathrm{CO}_{2}$ entitlements: implications for economic development. J Environ Dev 2(1):1-36

Rose A, Zhang ZX (2004) Inter-regional burden-sharing of greenhouse gas mitigation in the United States. Mitig Adapt Strateg Glob Chang 9:477-500

Tietenberg T (2006) Emissions trading: principles and practice. Washington, DC: Resources for the Future. United Nations Framework Convention on Climate Change (UNFCCC), 1992, Rio de Janeiro

Wang A (2013) The search for sustainable legitimacy: environmental law and bureaucracy in China. Harv Envtl L Rev 37:365-440

Wei C, Ni J, Du L (2011) Regional allocation of carbon dioxide abatement in China. China Econ Rev 23(3):552-565

Yi WJ, Zou LL, Guo J, Wang K, Wei YM (2011) How can China reach its $\mathrm{CO}_{2}$ intensity reduction targets by 2020? A regional allocation based on equity and development. Energ Policy 39(5):2407-2415

Zhang D, Rausch S, Karplus V (2013) Quantifying regional economic impacts of $\mathrm{CO}_{2}$ intensity targets in China. Ener Econ 40:687-701 